\title{
Homonymous Hemianopsia Associated with Probable Alzheimer's Disease
}

\author{
Akiko Ishiwata and Kazumi Kimura
}

\author{
Departments of Neurological Science, Graduate School of Medicine, Nippon Medical School, Tokyo, Japan
}

Posterior cortical atrophy (PCA) is a rare neurodegenerative disorder that has cerebral atrophy in the parietal, occipital, or occipitotemporal cortices and is characterized by visuospatial and visuoperceptual impairments. The most cases are pathologically compatible with Alzheimer's disease (AD). We describe a case of PCA in which a combination of imaging methods, in conjunction with symptoms and neurological and neuropsychological examinations, led to its being diagnosed and to AD being identified as its probable cause. Treatment with donepezil for 6 months mildly improved alexia symptoms, but other symptoms remained unchanged. A 59-year-old Japanese woman with progressive alexia, visual deficit, and mild memory loss was referred to our neurologic clinic for the evaluation of right homonymous hemianopsia. Our neurological examination showed alexia, constructional apraxia, mild disorientation, short-term memory loss, and right homonymous hemianopsia. These findings resulted in a score of 23 (of 30) points on the Mini-Mental State Examination. Occipital atrophy was identified, with magnetic resonance imaging (MRI) showing left-side dominance. The MRI data were quantified with voxel-based morphometry, and PCA was diagnosed on the basis of these findings. Single photon emission computed tomography with ${ }^{123} \mathrm{I}-\mathrm{N}$-isopropyl-p-iodoamphetamine showed hypoperfusion in the corresponding voxel-based morphometry occipital lobes. Additionally, the finding of hypoperfusion in the posterior associate cortex, posterior cingulate gyrus, and precuneus was consistent with $\mathrm{AD}$. Therefore, the PCA was considered to be a result of AD. We considered Lewy body dementia as a differential diagnosis because of the presence of hypoperfusion in the occipital lobes. However, the patient did not meet the criteria for Lewy body dementia during the course of the disease. We therefore consider including PCA in the differential diagnoses to be important for patients with visual deficit, cognitive impairment, and cerebral atrophy in the parietal, occipital, or occipitotemporal cortices. A combination of imaging methods, including MRI and single photon emission computed tomography, may help identify probable causes of PCA. (J Nippon Med Sch 2016; 83: 87-92)

Key words: posterior cortical atrophy, Alzheimer's disease, single photon emission computed tomography, magnetic resonance imaging, homonymous hemianopsia

\section{Introduction}

Posterior cortical atrophy (PCA) was first reported in a series of 5 cases by Benson et al in 1998. This rare neurodegenerative disorder occurs at a relatively young age with cerebral atrophy in the parietal, occipital, or occipitotemporal cortices and is characterized by visuospatial and visuoperceptual impairment in the absence of primary ophthalmologic findings. Originally, PCA was thought to be an independent disease; however, the majority of the disorder is pathologically compatible with Alzheimer's disease (AD). Other disorders reported to be associated with PCA include Lewy body dementia (DLB), corticobasal degeneration (CBD), and prion disease $\mathrm{e}^{2-6}$.

On the basis of the primary disorders of PCA, imaging findings may be variable. Cross-sectional magnetic resonance imaging (MRI) voxel-based morphometry has shown widespread differences in gray matter between patients with PCA and healthy persons, with the most significant reductions found most often in regions of the occipital and parietal lobes and then followed by areas in the temporal lobe ${ }^{7,8}$. In addition, in patients with symptoms for 5 or more years, atrophy is widespread

Correspondence to Akiko Ishiwata, MD, PhD, Department of Neurological Science, Graduate School of Medicine, Nippon Medical School, 1-1-5 Sendagi, Bunkyo-ku, Tokyo 113-8603, Japan

E-mail: akiko081@nms.ac.jp

Journal Website (http://www.nms.ac.jp/jnms/) 
throughout the cortex, including medial temporal lobe structures 9 . In comparison with AD, PCA demonstrates characteristic marked atrophy of the occipital lobe ${ }^{10}$. Several studies have found asymmetric atrophy patterns in PCA, but these differences could be due to selective biases in the diagnosis or to the inclusion of patients with prominent visual dysfunction ${ }^{11}$.

Data from functional imaging studies with single photon emission computed tomography (SPECT) and fluorodeoxyglucose positron emission tomography are largely consistent with structural changes in parieto-occipital areas $^{10,12-16}$. Positron emission tomography has also shown that the bilateral frontal eye fields, in addition to posterior regions, contain specific areas of hypometabolism, which can occur secondary to loss of input from occipitoparietal regions and may cause oculomotor apraxia in $\mathrm{PCA}^{10,17}$.

Although several studies have involved the neuroimaging of PCA, we now report a case in which the typical symptomatology, i.e., characteristic MRI features and identification by SPECT of $\mathrm{AD}$ as a probable cause of PCA, helped the diagnostic process of this rare neurodegenerative disorder.

\section{Case Report}

A 59-year-old, right-handed Japanese housewife with 16 years of education complained of a progressive visual deficit and loss of ability to read Japanese for 17 months and of a mild memory loss for 15 months before presenting to an outside ophthalmology clinic and an outside psychiatric clinic. At the ophthalmology clinic, right homonymous hemianopsia was diagnosed. However, no diagnostic details regarding the cause of this condition or other relevant information were provided for the patient's referral to the psychiatric clinic. At the psychiatric clinic, she could not understand the questionnaire and did not answer any questions. The Mini-Mental State Examination, which had a score of 27 (of 30) points, revealed delayed recall, reading impairment, and constructional apraxia.

Three months after being examined at the ophthalmologic and psychiatric clinics, the patient was referred to our neurologic clinic for evaluation of the right homonymous hemianopsia. The score of the Mini-Mental State Examination had decreased in 3 months from 27 to 23 of 30 points (disorientation -3 ; delayed recall -2 ; and reading impairment -1 ; and constructional apraxia -1 ). Motor, sensory, and coordination examinations during the neurological examination showed no relevant find- ings. Also present were right homonymous hemianopsia, constructional apraxia, and alexia characterized by PCA. On the other hand, not present were simultanagnosia, visual field deficit, and Gerstmann syndrome, which may be seen in PCA. Results of standard tests were as follows: Alzheimer's Disease Assessment Scale-cognitive subscale, 12.3 of 70; Wechsler Adult Intelligence Scale: Verbal Intelligence Quotient, 90; Physical Intelligence Quotient, 52; and Total Intelligence Quotient, 68. The patient's medical history, family history, and lab tests were unremarkable.

The patient was suspected to have PCA on the basis of occipital atrophy on an MRI scan performed at an outside hospital, alexia, right homonymous hemianopsis, and constructional apraxia. To further characterize features of PCA, MRI voxel-based morphometry and SPECT were performed in our hospital.

The MRI exam was performed with a 1.5-T Vision Plus scanner (Genesis Signa HDx, GE, Location) in our hospital. The MRI of the brain showed atrophy in the bilateral occipital lobes with more prominent atrophy in the left occipital lobe. In addition, a hyperintense signal was seen in the subcortical white matter of the bilateral occipital lobes, and volume loss was noted in the white matter (Fig. 1). The brain MR angiography demonstrated no luminal stenosis. No abnormalities were present in the posterior cerebral arteries.

\section{MRI Volumetry}

A total of 140 sections of a 3-dimensional T1-weighted magnetization-prepared rapid acquisition gradient echo sequence were obtained in a sagittal orientation as 1.2$\mathrm{mm}$ thick slices. Voxel-based specific regional analysis for Alzheimer's disease was performed with the method proposed by Matsuda et $\mathrm{al}^{18}$. In summary, brain MR images were segmented into gray matter, white matter, and cerebrospinal fluid images, which were then spatially normalized to a customized template in the standardized anatomic space. Each segmented gray matter image was compared with the mean and standard deviation (S.D.) of normal gray matter images acquired from 80 healthy subjects (37 men and 43 women; age range, 54 to 86 years; mean age, 70.4 \pm 7.8 years) with no memory impairment or cognitive disorders by means of a voxel-byvoxel Z-score analysis after voxel normalization to global mean intensities: Z-score $=($ control mean - individual value)/control S.D. These Z-score maps were displayed by overlay on tomographic sections and surface rendering of the standardized brain. This program registered the target volume of interest, defined by the aforemen- 

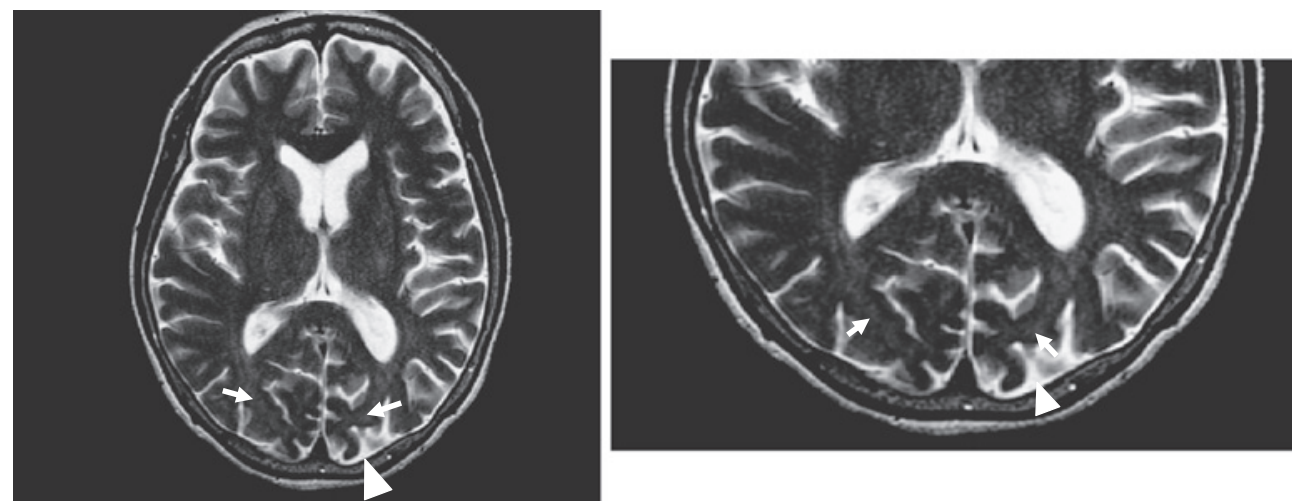

Fig. 1 T2-weighted magnetic resonance image

Atrophy in bilateral occipital lobes is noted. Atrophy in the left occipital lobe is more prominent (arrowheads). In addition, hyperintense signal in subcortical white matter of the bilateral occipital lobes is noted, and volume loss in the white matter was also seen (arrows).

\section{Z-score $2 \square 6$}
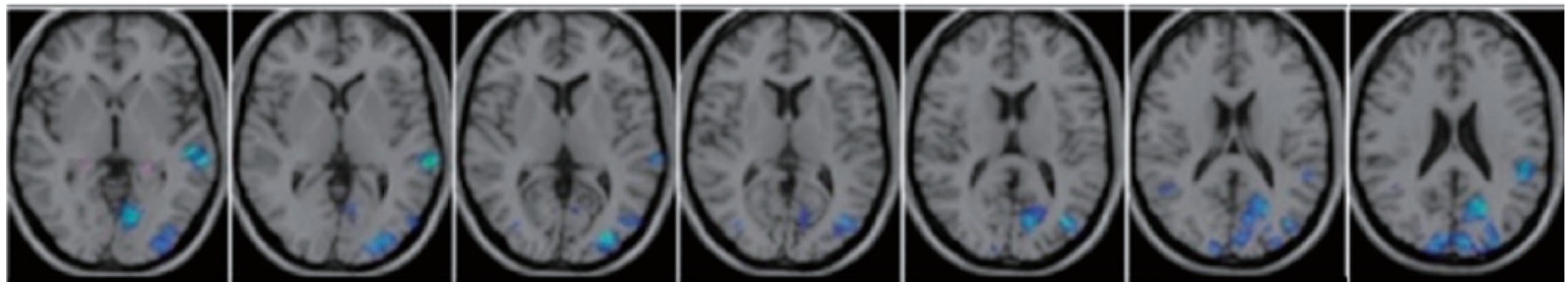

Fig. 2 Magnetic resonance volumetry

There is left predominant occipital cortical atrophy compared with the same age group of normal subjects.

tioned group comparison. Significant occipital atrophy was identified with volumetry compared with that of a group of healthy subjects of the same age (Fig. 2).

\section{SPECT Imaging}

Statistical mapping was performed with the following method. A fully automated 3-dimensional stereotactic surface projection technique was used to analyze the $\left[{ }^{123} \mathrm{I}\right]-$ $\mathrm{N}$-isopropyl-p-iodoamphetamine SPECT images $^{19}$. In brief, each SPECT image set was co-registered and warped to the common stereotactic coordinate system. Gray matter perfusion was then extracted to predefined surface pixels on a pixel-by-pixel basis. The images created by the projection of pixels to the brain surface were defined as surface mapping images. The extent and significance of perfusion reduction were assessed on a Zscore map. The Z-score was defined as (normal mean patient value)/normal SD. Low perfusion in the lateral and medial occipital lobes is seen on the surface mapping image and the Z-score image. Low perfusion is also seen in the parietal lobe and precuneus (Fig. 3).

\section{Differential Diagnosis}

In the differential diagnoses of homonymous hemianopsia, any involvement from the optic tracts to the optic radiation because of cerebral vascular diseases, tumors, infection, or trauma should be considered. In this patient, none of these was visualized on imaging. However, occipital atrophy was noted with MRI and statistical mapping. On the other hand, brain functional imaging with SPECT demonstrated hypoperfusion in the parietal lobe, posterior associate cortex, posterior cingulate gyrus, and precuneus, in addition to medial and lateral occipital gyri. Although these findings can be seen in DLB, the patient did not display any parkinsonism, rapid eye movement sleep behavior disorder, severe neuroleptic sensitivity, fluctuating attention and concentration, or recurrent well-formed visual hallucinations. Therefore, this patient did not meet the diagnostic criteria of DLB from the third DLB international workshop ${ }^{20}$. On pathology, the majority of PCA is composed of AD. The minority of PCA is composed of DLB, CBD and prion disease ${ }^{2-6}$. In 


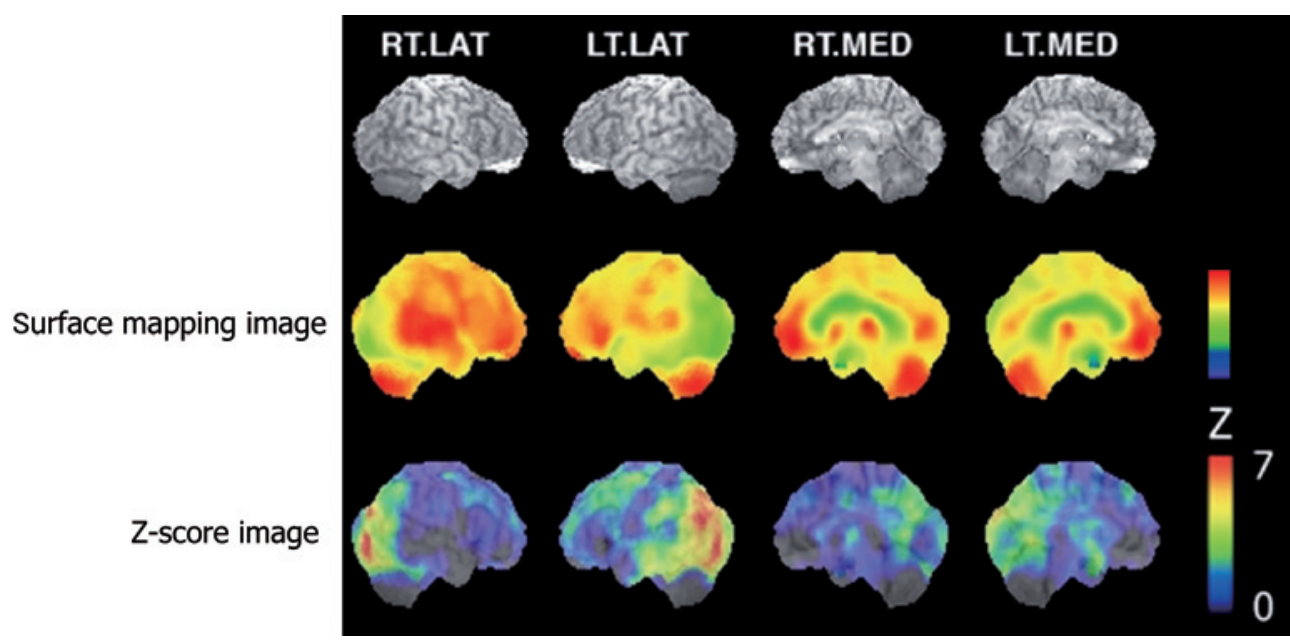

Fig. 3 Single photon emission computed tomography image

Surface mapping image (second row) and Z-score image (third row). The images created by the projection of pixels to the brain surface were defined as surface mapping images. On surface mapping images, the color gradation bar represents qualitative degree of cerebral perfusion impairment. Green represents relatively lower perfusion whereas red represents normal perfusion. Hypoperfusion is seen in the lateral and medial occipital lobes.

The Z-score images were normalized with cerebellar perfusion. Color coding represents Z-scores compared with age-matched normal controls. Red represents more significant perfusion reduction. There is hypoperfusion in the lateral and medial occipital lobes on the Z-score image. There is also hypoperfusion in the parietal lobe and precuneus. Note: Right lateral (RT.LAT), left lateral (LT.LAT), right medial (RT.MED) and left medial (LT.MED) views of brain.

this patient, DLB, CBD, and prion disease can be excluded on the basis of the clinical course and imaging manifestations. Therefore, PCA due to AD was diagnosed in this patient.

Our patient had findings consistent with PCA: a clinical course that matched that of PCA (slow progression and onset of visual field deficit), symptoms (alexia and constructional apraxia present without optic ataxia, motor paralysis, or sensory disturbance), and results of examinations (predominant posterior atrophy on MRI, and the Physical Intelligence Quotient of the Wechsler Adult Intelligence Scale was 25 to 30 points lower than the Verbal Intelligence Quotient) as proposed by Benson et al in 1988. Therefore, PCA was diagnosed.

We consider this patient to have a pathologic background of AD. Donepezil (an acetylcholinesterase inhibitor), at a dosage of $5 \mathrm{mg}$ /day, was started on the basis of the presumed diagnosis of early AD. The 6-month follow-up examination showed mild improvement in the alexia. However, no improvement was seen in visual deficit or constitutional apraxia, which could be due to the short length of follow-up.

\section{Discussion}

This case was diagnosed as PCA caused by AD and was treated with an acetylcholinesterase inhibitor. In the diagnostic process, evaluations were made according to a detailed history of symptoms and neurological findings; biochemical findings; hematologic findings; neuropsychiatric examination; cerebral morphologic evaluation, such as brain MRI; and functional brain imaging, such as SPECT. As a result, we determined the primary disease of our patient and were able to start the appropriate treatment.

For the treatment of PCA, no definitive protocol has been established. However, case reports have stated that PCA or a visual form of $\mathrm{AD}$ is responsive to cholinesterase inhibitors ${ }^{21,22}$. In both reports the responsiveness to cholinesterase inhibitors may be due to the causes of the PCA. We speculate that cholinesterase inhibitors may be effective for treating PCA in patients with AD.

The features of PCA proposed by Benson et al in 1988 include cerebral atrophy involving parietal, occipital, or occipitotemporal cortices as identified with computed tomography or MRI. However, functional brain imaging was not performed for the diagnosis. To the best of our 
knowledge, only 8 published studies have evaluated PCA with morphologic and functional imaging methods $^{12,23-28}$. In addition, the association of treatment with imaging examinations has not yet been reported. Functional imaging of the brain is considered useful for identifying functional abnormalities in such diseases as AD, DLB, or CBD, even before morphologic abnormalities are evident.

The present patient had cerebral atrophy in bilateral occipital lobes. She also had hyperintense lesions in the bilateral occipital subcortical white matter. These findings suggested that bilateral visual pathways were involved. Our findings are consistent with recent structural imaging studies of PCA. When compared with patients who had typical AD, patients who had PCA were found in structural imaging studies to have a greater global amyloid load in occipital and parietal regions, reduced white matter integrity in posterior regions, and severe white matter occipital atrophy ${ }^{11,29,30}$. In addition, patients who had PCA and homonymous hemianopsia were reported to have occipital and parietal white matter hyperintensity on T2-weighted images which could represent gliosis ${ }^{31}$. Furthermore, a recent diffusion-tensor MRI study has demonstrated both cortical and white matter atrophy ${ }^{32}$. These findings may provide new insights into PCA.

The present patient did not have parietal atrophy. The patient also did not have any symptoms of Gerstmann syndrome or Balint syndrome associated with parietal atrophy. The diagnosis of PCA was not made in the early stage because the patient showed only visual deficits during an ophthalmologic examination. A study investigating clinical features regarding PCA in patients whose visual deficit could not be explained by ophthalmology found pronounced involvement in the occipitoparietal regions; this involvement was found in many patients with simultanagnosia or less uncommon visual field defects $(47.5 \%)^{5}$.

The treatment and prognosis have not been well established. Because PCA is, in a majority of cases, composed of $\mathrm{AD}$, an acetylcholinesterase inhibitor is expected to have therapeutic effects. Case reports describing the effectiveness of this therapy have been published ${ }^{21,22}$. Approaches for treating PCA include localization of cerebral atrophy and imaging studies to identify the primary disease. We consider the present patient to have a pathologic background of AD. Treatment with the acetylcholinesterase inhibitor donepezil at a dosage of $5 \mathrm{mg}$ / day was started on the basis of a presumed diagnosis of the early stage of AD. At the 6-month follow-up exami- nation, mild improvement was seen in the alexia; however, no improvement was seen in visual deficits or constitutional dysplexia, perhaps because of the short length of treatment.

\section{Take Home Message}

- Cognitive dysfunction with visual deficits should be considered in patients with PCA.

- Both morphology and function should be evaluated in cases of PCA. Specifically, evaluation of the diseasespecific occipital atrophy with MRI and evaluation of $\mathrm{AD}$, as a probable cause of PCA, should be performed with SPECT.

Acknowledgements: The authors thank Dr. Baocheng Chu and Zach Miller for English revisions.

Conflict of Interest: The authors declare that they have no conflicts of interest.

\section{References}

1. Benson DF, Davis RJ, Snyder BD: Posterior cortical atrophy. Arch Neurol 1988; 45: 789-793.

2. Ala TA, Frey WH 2nd, Clark HB: Posterior cortical atrophy: Neuropathological correlations. Arch Neurol 1996; 53: 958.

3. Berthier ML, Leiguarda R, Starkstein SE, Sevlever G, Taratuto AL: Alzheimer's disease in a patient with posterior cortical atrophy. J Neurol Neurosurg Psychiatry 1991; 54: 1110-1111.

4. Renner JA, Burns JM, Hou CE, McKeel DW Jr, Storandt M, Morris JC: Progressive posterior cortical dysfunction: A clinicopathologic series. Neurology 2004; 63: 1175-1180.

5. Tang-Wai DF, Graff-Radford NR, Boeve BF, Dickson DW, Parisi JE, Crook R, Caselli RJ, Knopman DS, Petersen RC: Clinical, genetic, and neuropathologic characteristics of posterior cortical atrophy. Neurology 2004; 63: 1168-1174.

6. Victoroff J, Ross GW, Benson DF, Verity MA, Vinters HV: Posterior cortical atrophy. Neuropathologic correlations. Arch Neurol 1994; 51: 269-274.

7. Whitwell JL, Jack CR Jr, Kantarci K, Weigand SD, Boeve BF, Knopman DS, Drubach DA, Tang-Wai DF, Petersen $\mathrm{RC}$, Josephs KA: Imaging correlates of posterior cortical atrophy. Neurobiol Aging 2007; 28: 1051-1061.

8. Lehmann M, Crutch SJ, Ridgway GR, Ridha BH, Barnes J, Warrington EK, Rossor MN, Fox NC: Cortical thickness and voxel-based morphometry in posterior cortical atrophy and typical Alzheimer's disease. Neurobiol Aging 2011; 32: 1466-1476.

9. Lehmann M, Barnes J, Ridgway GR, Ryan NS, Warrington EK, Crutch SJ, Fox NC: Global gray matter changes in posterior cortical atrophy: A serial imaging study. Alzheimers Dement 2012; 8: 502-512.

10. Kas A, de Souza LC, Samri D, Bartolomeo P, Lacomblez L, Kalafat M, Migliaccio R, Thiebaut de Schotten M, Cohen L, Dubois B, Habert MO, Sarazin M: Neural correlates of cognitive impairment in posterior cortical atrophy. Brain 2011; 134: 1464-1478.

11. Crutch SJ, Lehmann M, Schott JM, Rabinovici GD, Rossor 
MN, Fox NC: Posterior cortical atrophy. Lancet Neurol 2012; 11: 170-178.

12. Aharon-Peretz J, Israel O, Goldsher D, Peretz A: Posterior cortical atrophy variants of Alzheimer's disease. Dement Geriatr Cogn Disord 1999; 10: 483-487.

13. Gardini S, Concari L, Pagliara S, Ghetti C, Venneri A, Caffarra P: Visuo-spatial imagery impairment in posterior cortical atrophy: A cognitive and SPECT study. Behav Neurol 2011; 24: 123-132.

14. Goethals M, Santens P: Posterior cortical atrophy. Two case reports and a review of the literature. Clin Neurol Neurosurg 2001; 103: 115-119.

15. Pietrini P, Furey ML, Graff-Radford N, Freo U, Alexander GE, Grady CL, Dani A, Mentis MJ, Schapiro MB: Preferential metabolic involvement of visual cortical areas in a subtype of Alzheimer's disease: Clinical implications. Am J Psychiatry 1996; 153: 1261-1268.

16. Wakai M, Honda $\mathrm{H}$, Takahashi A, Kato $\mathrm{T}$, Ito $\mathrm{K}$, Hamanaka T: Unusual findings on PET study of a patient with posterior cortical atrophy. Acta Neurol Scand 1994; 89: 458-461.

17. Nestor PJ, Caine D, Fryer TD, Clarke J, Hodges JR: The topography of metabolic deficits in posterior cortical atrophy (the visual variant of Alzheimer's disease) with FDGPET. J Neurol Neurosurg Psychiatry 2003; 74: 1521-1529.

18. Matsuda H, Mizumura $S$, Nemoto $K$, Yamashita $F$, Imabayashi E, Sato N, Asada T: Automatic voxel-based morphometry of structural MRI by SPM8 plus diffeomorphic anatomic registration through exponentiated lie algebra improves the diagnosis of probable Alzheimer disease. AJNR Am J Neuroradiol 2012; 33: 1109-1114

19. Minoshima S, Frey KA, Koeppe RA, Foster NL, Kuhl DE: A diagnostic approach in Alzheimer's disease using threedimensional stereotactic surface projections of fluorine-18FDG PET. J Nucl Med 1995; 36: 1238-1248.

20. McKeith IG, Dickson DW, Lowe J, Emre M, O'Brien JT, Feldman H, Cummings J, Duda JE, Lippa C, Perry EK, Aarsland D, Arai H, Ballard CG, Boeve B, Burn DJ, Costa D, Del Ser T, Dubois B, Galasko D, Gauthier S, Goetz CG, Gomez-Tortosa E, Halliday G, Hansen LA, Hardy J, Iwatsubo T, Kalaria RN, Kaufer D, Kenny RA, Korczyn A, Kosaka K, Lee VM, Lees A, Litvan I, Londos E, Lopez OL, Minoshima S, Mizuno Y, Molina JA, MukaetovaLadinska EB, Pasquier F, Perry RH, Schulz JB, Trojanowski JQ, Yamada M: Diagnosis and management of dementia with Lewy bodies: Third report of the DLB consortium. Neurology 2005; 65: 1863-1872.

21. Kim E, Lee Y, Lee J, Han SH: A case with cholinesterase inhibitor responsive asymmetric posterior cortical atrophy. Clin Neurol Neurosurg 2005; 108: 97-101.
22. Warren S, Hier DB, Pavel D: Visual form of Alzheimer's disease and its response to anticholinesterase therapy. J Neuroimaging 1998; 8: 249-252.

23. Andrade K, Kas A, Valabregue R, Samri D, Sarazin M, Habert MO, Dubois B, Bartolomeo P: Visuospatial deficits in posterior cortical atrophy: Structural and functional correlates. J Neurol Neurosurg Psychiatry 2012; 83: 860863.

24. Mizuno M, Sartori G, Liccione D, Battelli L, Campo R: Progressive visual agnosia with posterior cortical atrophy. Clin Neurol Neurosurg 1996; 98: 176-178.

25. Pedrosa R, Teixeira-Sousa V, Fonseca S, Bastos-Leite AJ: Early-onset Alzheimer disease: The contribution of neuroimaging for the diagnosis. Psychiatry Res 2010; 182: 287288.

26. Rene R, Munoz S, Campdelacreu J, Gascon-Bayarri J, Rico I, Juncadella M, Arruga J: Complex visual manifestations of posterior cortical atrophy. J Neuroophthalmol 2012; 32: 307-312.

27. Ross SJ, Graham N, Stuart-Green L, Prins M, Xuereb J, Patterson K, Hodges JR: Progressive biparietal atrophy: An atypical presentation of Alzheimer's disease. J Neurol Neurosurg Psychiatry 1996; 61: 388-395.

28. Teichmann M, Kas A, Boutet C, Ferrieux S, Nogues M, Samri D, Rogan C, Dormont D, Dubois B, Migliaccio R: Deciphering logopenic primary progressive aphasia: A clinical, imaging and biomarker investigation. Brain 2013; 136: 3474-3488.

29. Formaglio M, Costes N, Seguin J, Tholance Y, Le Bars D, Roullet-Solignac I, Mercier B, Krolak-Salmon P, Vighetto A: In vivo demonstration of amyloid burden in posterior cortical atrophy: A case series with PET and CSF findings. J Neurol 2011; 258: 1841-1851.

30. Migliaccio R, Agosta F, Possin KL, Rabinovici GD, Miller BL, Gorno-Tempini ML: White matter atrophy in Alzheimer's disease variants. Alzheimers Dement 2012; 8: S78-87 e71-72.

31. Schmidtke K, Hull M, Talazko J: Posterior cortical atrophy: Variant of Alzheimer's disease? A case series with PET findings. J Neurol 2005; 252: 27-35.

32. Caso F, Agosta F, Mattavelli D, Migliaccio R, Canu E, Magnani G, Marcone A, Copetti M, Falautano M, Comi G, Falini A, Filippi M: White matter degeneration in atypical Alzheimer disease. Radiology 2015; 277: 162-172.

(Received, August 28, 2015)

(Accepted, November 11, 2015) 